\section{Triathlon challenge - from craggy to crazzy a different kind of pain management program}

\author{
Michael G Serpell* \\ Department of Anaesthesia, Queen Elizabeth University Hospital, Glasgow, UK
}

\section{Ironman Wales sept $14^{\text {th }} 2014$}

Sea swim (2.4 mile), bike ride (112 mile) and Marathon (26 mile), all in one day!

There are lessons that the 7.8 million UK Chronic Pain patients can learn from the world of endurance sports, and vice versa [1]. The training, psychological tools and strategies used by athletes to complete an endurance event, are equally relevant for those with chronic pain, who wish to regain some form of "normal" life if treatment therapies have failed $[2,3]$.

This is my reflection of how, using some of the techniques involved in Pain Management Programs, I trained for an Ironman Triathlon in just over one year.

\section{Ironman Wales - how did I get there?}

It started with my first ever triathlon event, just off Oban, Scotland in August 2013. The "Craggy Island" triathlon is a very popular bespoke event. It involves a short seawater swim (550m) from the mainland to Kerrera Island, then a $14 \mathrm{~K}$ mountain bike ride, followed by an $8 \mathrm{~K}$ cross-county hill run. The short swim was what attracted me, as I could not swim more than two lengths of a pool without gasping for air. Swim training started six weeks before race day. Slowly I was able to build up my tolerance to 22 lengths of a $25 \mathrm{~m}$ pool. I was ready, right? (Pre-contemplation - Appendix \& Figure 1).

Wrong! A sea swim is completely different from a pool swim. Cold and choppy is the water, and you can't see what lurks below! It was a memorable introduction for me to the world of open triathlon. Swallowing mouthfuls of saltwater, unable to immerse my head for more than a few strokes due to the cold and fear, and nearly drowning on three occasions. This is what I remember! However, I survived and made it to shore, and crawled into the transition area for the bike phase. Surprisingly I was not the last one out of the drink, but by the time my frozen hands extracted me out of my wetsuit, and tied up my shoelaces, I was last in the pack. Not a good start, but as I warmed up and established a rhythm, I clawed my way up

\section{More Information}

*Address for Correspondence: Michael G Serpell, Department of Anaesthesia, Queen Elizabeth University Hospital, Glasgow, UK, Tel: +07931465412/0141355 1491; Email: mgserpell@cheerful.com

\section{Submitted: 01 July 2019 \\ Approved: 22 July 2019 \\ Published: 23 July 2019}

How to cite this article: Serpell MG. Triathlon challenge - from craggy to crazzy a different kind of pain management program. J Sports Med Ther. 2019; 4: 050-052.

DOI: 10.29328/journal.jsmt.1001043

Copyright: @ 2019 Serpell MG. This is an open access article distributed under the Creative Commons Attribution License, which permits unrestricted use, distribution, and reproduction in any medium, provided the original work is properly cited

Check for updates

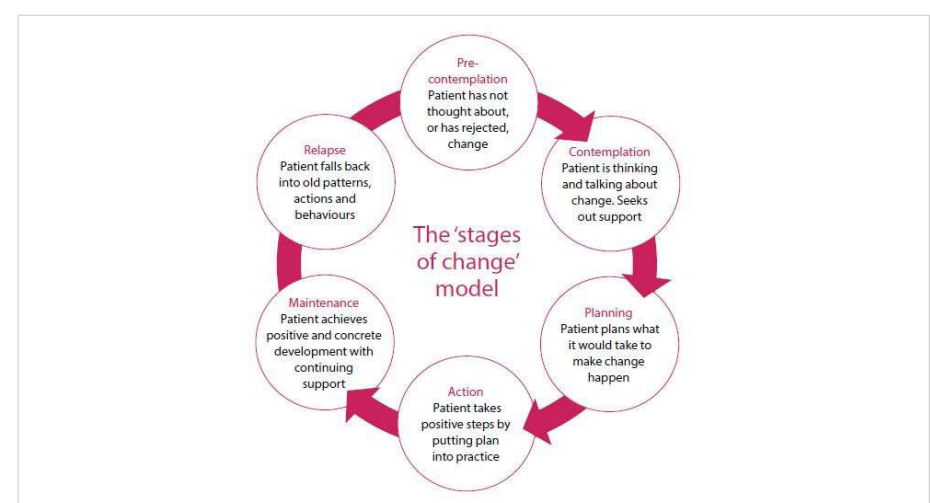

Figure 1: Illustration of the Transtheoretical Model of Behaviour Change. Accessed 22/7/19, https://www.chemistanddruggist.co.uk/cpd-article/supporting-smokers-quit-0

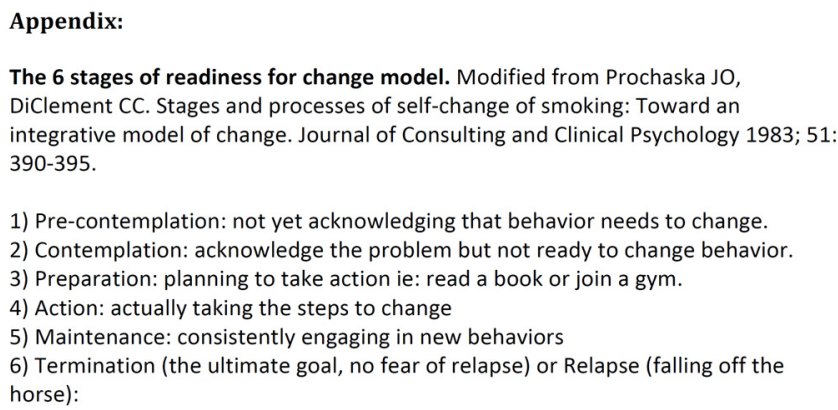

The 6 stages of readiness for change model. Modified from Prochaska JO, DiClement CC. Stages and processes of self-change of smoking: Toward an integrative model of change. Journal of Consulting and Clinical Psychology 1983; 51 390-395.

1) Pre-contemplation: not yet acknowledging that behavior needs to change. 2) Contemplation: acknowledge the problem but not ready to change behavior. 3) Preparation: planning to take action ie: read a book or join a gym.

4) Action: actually taking the steps to change

5) Maintenance: consistently engaging in new behaviors

6) Termination (the ultimate goal, no fear of relapse) or Relapse (falling off the horse):

Mindfulness - "paying attention in a particular way: on purpose, in the present moment, and non-judgmentally". Jon Kabat-Zinn

Appendix

(literally on some of those hills!) to finish in just over 2 hours, with a placing in the middle of the competitors.

I had survived! Feelings of immense satisfaction and 
disbelief, hit me at the same time. And rather strangely, I had enjoyed myself. If I were to do this again though, I would need to be much, much better prepared (Contemplation).

Over the next two months I pondered. I read books on triathlon training (Can't Swim, Can't Ride, Can't Run by Andy Holgate, and Be Iron Fit by Don Fink), focusing particularly on time management (Preparation). Could I actually devote the time required to give it serious merit? I decided to bite the bullet and booked a triathlon event as late in the 2014 season as possible (goal setting) in order to give me the maximum amount of time before serious training needed to begin. The 30 -week training program would therefore not need to start until well after the Christmas holidays! I enjoy my food and drink a little too much (boom and bust).

It started in January 2014 with the " $5 \mathrm{~K}$ challenge" (Action). The challenge is to run $5 \mathrm{~K}$, or for 30 minutes, every day for the whole of the month. Sounds easy! Nevertheless, it is a real test of commitment, to do it every single day, for 31 consecutive days, especially during that dark and miserable month. On some days the run was done at $4 \mathrm{AM}$, before going to the airport, or at 11.30 PM, after a busy day at work. But I completed the challenge, and knew then, that the task I had set myself was possible. (The author is an academic Anaesthetist, which involves clinical days in the Operating Theatre, and attendance at research and education meetings around the UK and Europe).

The hard part had been done. I had demonstrated time management and commitment. What I needed to do now was simply follow the 30-week recipe. Most of my training was done solo because of the unsocial hours and travelling required in my work. However, I joined two Triathlon clubs because I worked and lived in two different areas (Fusion in Glasgow, and Loch Lomond) for coaching input and some company, and I did an intensive weekend swim course (Total Immersion). I aimed optimistically for the "Intermediate" program (1015 hours per week), but within a month had slipped into the "Just complete" program because of time commitments. Nonetheless, I had a program (7-10 hours per week), and training got easier as the routine was established and spring brought longer days and better weather (Maintenance).

I had never intended to do a full Ironman. I booked it, as there was no other triathlon event that was late enough in the season, and which didn't clash with holiday or work events. I naively thought that if I was doing the training for a half Ironman, it couldn't be much more effort to train for a full one! My 30-week schedule factored in practice events such as a Standard (Olympic) distance (Northumberland Triathlon, June $8^{\text {th }}$ ) and a half Ironman distance (Cleveland Steelman, July $19^{\text {th }}$ ). These were important rehearsals, they revealed my weaknesses (fitness, technique and equipment), and gave me specific areas to focus on (how to fix a flat tire and bike chain in mid-race, how not to forget to bring a wetsuit and have to borrow one that was two sizes too small!). However, completing these events also gave me confidence and a belief, that the big race was achievable.

\section{Ironman Wales - how did I get through?}

So the big day finally arrived, and much quicker than expected too. I'll not go into great detail, as there are many accounts available on various triathlon blogs. However, I would like to share what I think are two important lessons from my day.

I got down to Wales early. Right up until the week before, I had planned to arrive the day before. The closer I got to the event, the more I realized that mental preparation was absolutely essential before the race. So, I drove the 500 miles straight down from work (4 hours sleep in Cardiff), to arrive in Tenby two days before the race for the first practice swim.

There was a sea swell of up to two feet. The forecast was for an even bigger swell on race day! I spent the next two mornings just getting familiar with the conditions, learning to be comfortable and to "love" the water. Thanks to my practice sessions in Loch Lomond, cold-water temperature was not an issue. On race day Sunday, the sea swell did not look so bad when we started at $7 \mathrm{AM}$. It soon picked up however, and caused a major problem. Many were seasick and vomiting, over a hundred swimmers were pulled out, and the swim stage was very nearly cancelled. I was not ignorant of these facts, as I was either being tossed up in the air by waves, or buried under them in an avalanche of water. I didn't try to fight the conditions, I was relaxed and calm, and accepted them (mindfulness). The next day in my hotel, I met a seasoned Ironman from Barcelona who was packing his "state of the art" road bike. He said he had never experienced such cold and rough waves, and did not finish the swim. I strongly believe that without those two preparation days, I would not be writing this story in quite the same way.

The second lesson is "Pace and Graze". This is common knowledge amongst competitors, but putting it into practice can be difficult. The temptation is to fire off and chase the others in the bike section. If you do, it's more than likely you will hit the "wall" towards the end, as you may not have enough fuel left in the tank. The bike section is where you do most of your eating and drinking ( 150 calories every 20 minutes, 500$1000 \mathrm{ml}$ of fluids every hour) because it's harder to eat and drink whilst running. When you consider that breakfast $(1,000$ calories) was three hours before the swim, which started two hours ago, you expect and need to be back in the full digestion process. Usually, it is a matter of getting into a steady bike pace and start consuming!! But, after THAT SWIM, the nausea put paid to oral intake for nearly an hour. It is hard holding back on the pace, but it returns dividends later on when you can start to gradually increase momentum and reel in those riders who went off too soon and are now fading. One other competitor from my hotel told me he felt so nauseous he could 
not take anything by mouth for three hours after starting the bike, but he held steady and eventually completed!

To reach the third and final marathon section was a relief, I knew then that, barring an accident, I would complete. I had only ever run a couple of half marathon distances during my training, but I knew that I could jog, shuffle, walk or even crawl a full marathon distance if I needed to. I ran the first $10 \mathrm{~K}$, and then did a mix of walking uphill and shuffling on the flats and downhill. Also very important were the mandatory one-minute walk and fuel-ups at every single drink station! And all the while, the enthusiastic crowds lining the streets kept us all going. Their encouragement and genuine support was immense. It can never be overstated just how much it means to have people recognize and acknowledge the pain and effort you are struggling with (family and friends of pain patients please heed!).

After completion, those same feelings of immense satisfaction and disbelief, which I had experienced at Craggy Island, hit me again. Tenby was a fantastic experience, which
I will remember forever, and one that I would recommend everyone to try once in their lifetime. I will definitely repeat it one day, but for now, I'm enjoying the rest. This however, is a luxury that pain patients don't have. They have to run their marathon each and every day.

Will I relapse? Who knows, I'm only human. But I have a program, which I can follow. It's up to me, and it's my choice whether I reach termination.

\section{References}

1. Astin JA. Mind-Body Therapies for the Management of Pain. Clinical Journal of Pain. 2004; 20: 27-32. PubMed: https://www.ncbi.nlm.nih. gov/pubmed/14668653

2. Guidelines for Pain Management Programmes for adults. An evidence-based review prepared on behalf of the British Pain Society. https://www.britishpainsociety.org/static/uploads/resources/files/ pmp2013_main_FINAL_v6.pdf

3. National Pain Audit Final Report 2010-2012

4. https://www.britishpainsociety.org/static/uploads/resources/files/ members_articles_npa_2012_1.pdf 